\title{
DERECHO Y POLÍTICAS AMBIENTALES EN LA REGIÓN DE MURCIA
} (PRIMER SEMESTRE 2019)

\author{
Santiago M. Álvarez CARreño \\ Profesor Titular de Derecho Administrativo \\ Universidad de Murcia
}


Sumario: 1. Breve reflexión introductoria: de la aceleración legislativa al fracasado intento de demolición de las estructuras administrativas ambientales. 2. Manifestaciones de la política y legislación ambiental de la Administración regional en Murcia. 2.1. La aceleración a ninguna parte: la Ley 10/2018, de 9 de noviembre, de Aceleración de la Transformación del Modelo Económico Regional para la Generación de Empleo Estable de Calidad. 2.2. El intento de demolición de las estructuras administrativas al servicio de la protección ambiental: el proyecto de creación de la Agencia «ARCA». 2.3. El fracking en Murcia: la Ley 11/2018, de 15 de noviembre, por la que se establecen medidas adicionales de protección de la salud pública y del medio ambiente para la exploración, investigación o explotación de hidrocarburos utilizando la técnica de la fractura hidráulica en la Comunidad Autónoma de la Región de Murcia. 2.4. Los suelos contaminados por actividades mineras: El denominado «Plan de recuperación de suelos afectados por la minería metálica» (PRASAM). 3. Otras manifestaciones con contenido ambiental durante el periodo de referencia. 3.1. Contaminación por nitratos: un intento ya desesperado por salvar el Mar Menor. 3.2 El arruí: el negocio de la caza de una especie exótica, ¿no invasora? 3.3. Energías renovables. 3.4. La declaración de bienes de interés cultural. 3.5. Fauna invasora: Los problemas que causa la proliferación del conejo de monte. 3.6. Deporte y naturaleza: la necesidad de proteger los senderos. 3.7. Promoviendo las actividades agropecuarias de proximidad. 4. Final: una mala noticia para la anhelada recuperación ambiental de la bahía de Portmán.

\section{BREVE REFLEXIÓN INTRODUCTORIA: DE LA ACELERACIÓN LEGISLATIVA AL FRACASADO INTENTO DE DEMOLICIÓN DE LAS ESTRUCTURAS ADMINISTRATIVAS AMBIENTALES}

La presente crónica da cuenta de las novedades, algunas de bastante enjundia, de la política y legislación ambiental en la Región de Murcia durante este primer semestre del 2019. No obstante, nuestro fiel lector o lectora apreciará la inclusión de tres referencias producidas a finales del pasado año que, por su tardía fecha de aprobación, no pudieron ser más que aludidas en la anterior crónica pero que merecían, sin duda, una mirada un tanto más atenta en la presente ocasión. Por lo demás, el ambiente electoral impregna desde hace ya tiempo e impregnará hasta la aparición de esta crónica, todos los rincones de la escena pública y, de manera un tanto sorprendente para este atribulado cronista, las cuestiones ambientales no ocupan un espacio destacado en ninguna de las discusiones y debates siendo, como son sin duda, las más esenciales para la suerte de esta especie homínida y del resto de subyugadas especies que surcan el espacio interestelar a bordo de este planeta, otrora azul, llamado «Tierra» pero que bien hubiera podido llamarse mejor «Agua».

2. MANIFESTACIONES DE LA POLÍTICA Y LEGISLACIÓN AMBIENTAL DE LA ADMINISTRACIÓN REGIONAL EN MURCIA 


\subsection{La aceleración a ninguna parte: la Ley $10 / 2018$, de 9 de noviembre, de aceleración de la transformación del modelo económico regional para la generación de empleo estable de calidad}

La Ley 10/2018, de 9 de noviembre, de Aceleración de la Transformación del Modelo Económico Regional para la Generación de Empleo Estable de Calidad de la Región de Murcia, lleva a cabo una nueva y profunda modificación de la Ley 4/2009, de 14 de mayo, de Protección Ambiental Integrada de la Región de Murcia, e incide, en el mismo sentido de las modificaciones anteriores de las que ya se ha ido dando cuenta en estas crónicas y en otras publicaciones de este mismo cronista ${ }^{1}$, en la tendencia — casi podría hablarse de una pulsión — por aligerar la intervención administrativa sobre las actividades económicas, simplificando su control ambiental cuando están sujetas a autorización ambiental integrada (AAI) o a otras autorizaciones sectoriales y desplazando, en otros casos, la responsabilidad hacia las siempre más frágiles Administraciones locales.

Así, por señalar algunas de las innovaciones, se establece que cuando resulte exigible una AAl ya no será preciso que el Ayuntamiento conceda licencia municipal a la actividad, de conformidad con el Texto refundido de la Ley de prevención y control integrados de la contaminación —Real Decreto Legislativo 1/2016, de 16 de diciembre. Por otro lado, se detalla la documentación que debe aportarse en las solicitudes de autorizaciones ambientales sectoriales, simplificando también la tramitación ambiental de actividades. Asimismo, se concretan los trámites dirigidos a la regularización de actividades en funcionamiento que carecen de título habilitante para su ejercicio, por una falta de adecuación en todas sus determinaciones al planeamiento urbanístico, en el marco de lo establecido en la Ley 4/2009 (arts. 138 y ss.), admitiéndose la

\footnotetext{
${ }^{1}$ Cfr. Álvarez Carreño, S. M. (2017), "Los riesgos ambientales en la política y legislación de la Comunidad Autónoma de la Región de Murcia”, en Conesa García, C. / PÉrez Cutillas, P. (eds.), Riesgos ambientales en la Región de Murcia, Editum - colección miradas, Universidad de Murcia, pp. 339-362; y, "El continuo "coser y descoser" de la legislación procedimental ambiental de la Región de Murcia", Actualidad Jurídica Ambiental, vol. 84, 5 de noviembre de 2018, pp. 1-8 (reeditado en BlASCO Hedo, E. / Mora Ruiz, M. (coord.) (2019), "20 años de la prevención y el control integrados de la contaminación. Balance y perspectivas", Actualidad Jurídica Ambiental, núm. especial 89- marzo 2019, pp. 199-207.
} 
autorización provisional de las mismas hasta que se modifique el planeamiento urbanístico (disposición adicional primera).

En relación con este señalado alcance simplificador de la Ley 10/2018, debe recordarse que la doctrina ha tratado de reaccionar a las modernas vías de liberalización ambiental como consecuencia de modificaciones normativas, avaladas en ocasiones por la propia interpretación jurisprudencial, con la formulación del principio de no regresión, mediante el que se trata de evitar este retroceso en los niveles de protección alcanzados. A través del mencionado principio se defiende que el estándar de protección ambiental logrado debe ser, no sólo respetado, nunca disminuido, sino más bien incrementado, y exige, para que su eventual sacrificio fuera admisible, la evidencia de que los intereses contrarios de naturaleza económica y social demuestren ser jurídicamente superiores al interés público ambiental, lo cual, desde luego, no puede suponerse en todo caso $^{2}$.

Es cierto que, aun tímidamente superada la crisis económica acaecida, los responsables políticos se encuentran constantemente en la encrucijada que supone encontrar un adecuado equilibrio entre la libertad y los derechos de los individuos, de la industria y de las empresas, por una parte, y la necesidad de reducir el riesgo de efectos adversos para el medio ambiente y la salud humana, animal o vegetal, por otra. Por ello, merece la pena recordar que hace ya tiempo que la Comisión Europea apeló al necesario equilibrio de intereses con el fin de justificar la adopción de las medidas proporcionadas, no discriminatorias, transparentes y coherentes, lo cual exige un proceso de toma de decisiones estructurado que cuente con información científica pormenorizada y con datos objetivos $^{3}$. Son muchos los riesgos no sólo ambientales sino incluso para el

\footnotetext{
${ }^{2}$ El estudio monográfico más completo en España sobre el principio de no regresión es el de AMAYA ARIAS, A. M. (2016), El principio de no regresión en el Derecho ambiental, Iustel, Madrid.

${ }^{3}$ Los principios de prevención y cautela incorporados al Tratado de Funcionamiento de la Unión Europea (art. 191 TFUE) implican igualmente la garantía del principio de no regresión en la medida que se adelantan a la producción del daño ambiental y se evita de este modo la producción de situaciones irreversibles. Vid. CIERCO SEIRA, C. (2004), "El principio de precaución: reflexiones sobre su contenido y alcance en los derechos comunitario y español", Revista de Administración Pública, núm. 163, pp. 73-125; DOMÉNECH PASCUAL, G. (2006), Derechos fundamentales y riesgos tecnológicos: el derecho del ciudadano a ser protegido por los poderes públicos, Centro de Estudios Políticos y Constitucionales, Madrid; EMBID TELLO, A. E. (2009), "El principio de precaución", en SANTAMARÍA PASTOR, J. A. (dir.), Los principios jurídicos del Derecho Administrativo, La Ley, Madrid; y, más recientemente, SORO MATEO, B. (2017),
} 
propio Estado de Derecho que plantean algunas de las cuestiones apuntadas rebaja en la protección y desregulación-que requieren una reconstrucción teórica que aborde globalmente esta cascada de cambios parciales que, desde una óptica desreguladora, ponen en riesgo nuestro futuro en común. El Derecho ambiental, de este modo, está actuando de nuevo como terreno de prueba de muchas de las transformaciones que, en virtud de diversos factores, está experimentando el ámbito y el papel reservado a los poderes públicos en su misión de garantizar objetivos de interés general ${ }^{4}$.

Finalmente, en este caso en la acertada dirección de favorecer a las energías renovables, la Ley 10/2018 establece medidas de agilización y simplificación para el acceso y la conexión de instalaciones generadoras de energía eléctrica basadas en fuentes de este tipo, tanto con vertido a red como autoconsumidoras, y se incide en el necesario papel ejemplarizante que la administración autonómica debe adoptar en el ahorro, eficiencia energética y uso de las energías renovables en sus edificios, instalaciones y parque móvil estableciendo la obligación de que el sector público regional logre una reducción del consumo de energía del $23 \%$ para el año 2020 y del $25 \%$ en el año 2025 , todo ello sobre el nivel base de referencia del consumo energético global existente. Se establece además la obligación de que los edificios de nueva construcción y ampliación de los existentes tanto de la Administración regional como del sector público institucional regional, incluidos los destinados a vivienda protegida, estén calificados como de consumo de energía casi nulo y se adoptan medidas sobre renovación de instalaciones, equipos, flotas y vehículos, que deben tomarse teniendo en cuenta el ahorro, la eficiencia energética, la utilización de energías renovables y la disminución del consumo de combustibles derivados del petróleo.

\footnotetext{
“Construyendo el principio de precaución”, Revista Aragonesa de Administración Pública, núm. 49-50, pp. 87-151.

${ }^{4}$ Cfr. Álvarez CARreño, S. M. (2018), "La evolución regresiva de la política y del derecho ambiental en España”, Revista Aranzadi de Derecho Ambiental, núm. 41, pp. 15-40.
} 


\subsection{El intento de demolición de las estructuras administrativas al servicio de la protección ambiental: el proyecto de creación de la agencia «ARCA»}

El Gobierno de la CARM ha manifestado en repetidas ocasiones su consideración de la Administración ambiental, representada básicamente por las Direcciones Generales de Medio Ambiente y de Medio Natural, poco menos que como un estorbo en sus intentos de favorecer un crecimiento económico significativo. Se debe recordar que estas dos direcciones generales gestionan un gran número de expedientes complejos, con gran cantidad de proyectos y actividades sometidos a informe, autorización, evaluación, control y seguimiento. Su estructura interna resulta, por una parte, totalmente insuficiente para llevar a cabo sus cometidos de manera satisfactoria y, por otra, se detecta una confusa definición de las competencias y atribuciones de los diferentes servicios que las componen. Se detecta, por otra parte, un claro déficit de puestos técnicos, además en su mayoría interinos, que dotan a estas estructuras organizativas de alto grado de provisionalidad y de precariedad ${ }^{5}$.

Estas manifiestas insuficiencias de medios y recursos (falta de medios informáticos, antigüedad del parque móvil...) generan además un clima de inseguridad entre los técnicos a la hora de ejercer sus funciones. Resulta evidente que la precariedad de recursos humanos y materiales, así como la debilidad organizativa de las dos direcciones generales, tiene un efecto directo en las deficiencias en la garantía efectiva de los derechos a la información pública y a la tutela ambiental efectiva. Los agentes económicos y sociales comprueban como los trámites se dilatan en el tiempo.

Para solucionar esta situación se podría comenzar por dotar las plazas con el personal funcionario técnico y administrativo necesario y mejorar los medios materiales puestos a disposición de la política ambiental en la CARM. Sin embargo, el partido en el Gobierno regional decidió seguir otra estrategia para

\footnotetext{
${ }^{5}$ La Dirección General del Medio Natural consta de 49 plazas cubiertas de manera definitiva, 44 interinas y 12 interinas llamadas "por programa". La Dirección General del Medio Ambiente y Mar Menor tiene 44 definitivas, 22 interinas, 12 interinas "por programa" y 10 interinas "por acumulación de tareas".

Así, más de la mitad del personal de estas dos direcciones generales es eventual o provisional. Los interinos por programa tienen contratos de tres años y no pueden tramitar expedientes ordinarios; y los interinos contratados por acumulación de tareas lo están por 6 meses, aunque sí pueden realizar trámites ordinarios. Por su parte, en el cuerpo de agentes medioambientales, donde existe mayor proporción de personal estable, se detectan igualmente situaciones de eventualidad ( 25 de 114 , es decir el $22 \%$ ).
} 
resolver este estado de cosas y presentó una iniciativa legislativa en la Asamblea regional que preveía la creación de la Agencia Regional del Clima y del Medio Ambiente (ARCA). En cierto modo, esta iniciativa formaba un formaba un pack con la de Aceleración de la Transformación del Modelo Económico Regional para la Generación de Empleo Estable de Calidad que finalmente fue aprobada como Ley 10/2018, de 9 de noviembre, como se acaba de reseñar. Esta segunda pata de la "reforma ambiental" sufrió sin embargo distinta suerte ya que el grupo Ciudadanos se ha desmarcado, por ahora...

La nueva Agencia, en el marco de la estrategia «Región de Murcia, Libertad Económica», cuyo objetivo declarado consiste en modificar los procedimientos administrativos para simplificarlos, pretendía - con el apoyo entusiasta de la Confederación Regional de Organizaciones Empresariales de Murcia (CROEM) - concentrar bajo una misma dirección las funciones de planificación ambiental, fomento del desarrollo sostenible e intervención administrativa sobre la evaluación y autorización ambiental de los planes, proyectos y actividades de mayor repercusión sobre el medio ambiente de la Región. De este modo, se profundizaba en las medidas de agilización y supresión de cargas burocráticas y se pretendía seguir modelos como el de la Agencia de Medio Ambiente y Agua de Andalucía, creada en 2011, o el del Instituto aragonés de Gestión Ambiental (INAGA) creado en 2003 y profundamente reformado en 2013.

Finalmente, como se señaló la iniciativa no prosperó por falta de apoyos parlamentarios y todo queda remitido al resultado de los próximos comicios electorales.

\subsection{El fracking en Murcia: la Ley $11 / 2018$, de 15 de noviembre, por la que} se establecen medidas adicionales de protección de la salud pública y del medio ambiente para la exploración, investigación o explotación de hidrocarburos utilizando la técnica de la fractura hidráulica en la Comunidad Autónoma de la Región de Murcia

Se debe saludar - este cronista no puede más que regocijarse de poder constatar, de tiempo en tiempo, los progresos en la protección de nuestro medio ambiente- como un verdadero aunque tímido avance, la aprobación de la Ley 
11/2018, de 15 de noviembre, por la que se establecen Medidas Adicionales de Protección de la Salud Pública y del Medio Ambiente para la Exploración, Investigación o Explotación de Hidrocarburos utilizando la Técnica de la Fractura Hidráulica en la Comunidad Autónoma de la Región de Murcia, que viene a paliar la insuficiencia de la regulación estatal en la materia ${ }^{6}$. El TC se ha mostrado repetidamente contrario a que las CCAA ostenten competencias para limitar y, mucho menos, prohibir esta actividad. La ley aprobada representa la segunda versión de un proyecto que, en términos parecidos a las fallidas leyes cántabra, navarra y riojana fueron anuladas por el TC por invadir competencias que corresponden al Estado, como la regulación energética o la de hidrocarburos ${ }^{7}$.

Puede decirse que la reciente Ley murciana sobre fracking resulta muy similar a la Ley castellano-manchega, que recibió el aval del TC, al no prohibir la fractura hidráulica sino solamente añadir requerimientos que se adjuntan a los ya establecidos por la normativa estatal.

La Ley de la CARM aduce en su exposición de motivos la escasez de recursos hídricos y los altos valores naturales presentes en la Región como fundamentos de la necesidad de establecer la obligación para la Administración regional de elaborar un plan estratégico sectorial para la utilización de esta técnica tras la evaluación de sus riesgos, en aplicación de los principios de prevención y cautela contemplados ya desde la normativa comunitaria, concretamente en el art. 191 TFUE, e incorporados a nuestro ordenamiento jurídico interno a través de la legislación de evaluación ambiental, concretamente en la actualidad, por la Ley

\footnotetext{
${ }^{6}$ En la doctrina $c f r$. RAmos MEdRANO, J. A. (2016), "La prohibición de actividades mineras en la ordenación territorial y urbanística, a la luz de la jurisprudencia“, Actualidad Jurídica Ambiental, núm. 62, 14 de noviembre de 2016; SANTAMARÍA ARINAS, R. (2014), "Las claves jurídicas del debate sobre el fracking", Revista Catalana de Dret Ambiental, vol. V, núm. 1, pp. 1-38; Moreu Carbonell, E. (2012), "Marco jurídico de la extracción de hidrocarburos mediante fractura hidráulica (fracking)", Revista Catalana de Dret Ambiental, vol. 3, núm. 2, pp. 1-43.

${ }^{7}$ Se deben traer a colación aquí, las SSTC 106/2014, de 24 de junio, contra la Ley de Cantabria; la 134/2014, de 22 de julio, contra la Ley de La Rioja; la 208/2014, de 15 de diciembre, contra la Ley Foral de Navarra; y, en fin, la STC 73/2016, de 14 de abril de 2016, contra la Ley catalana que pretendía establecer condiciones para la utilización de esta técnica. También resulta oportuno citar la STC 165/2016, de 6 de octubre (Ponente: NARVÁEZ RODRÍGUEZ) que resuelve el recurso de inconstitucionalidad presentado por el Gobierno de Aragón contra la Ley 40/2010, de 29 de diciembre, de almacenamiento geológico de dióxido de carbono y que, como pone de manifiesto el voto particular de la Magistrada ASUA BATARRITA, afecta a cuestiones similares a las planteadas por la técnica de fracturación hidráulica. La STC 8/2018, de 25 de enero, mantiene que la Ley vasca reduce, dificulta e impide la eficacia de la normativa básica del Estado, lo que las hace incompatibles entre sí.
} 
21/2013, de 9 de diciembre, de evaluación ambiental. El texto contempla que las consejerías competentes en salud pública, ordenación del territorio y energía aprobarán un Plan estratégico, en cuyo procedimiento de elaboración participará, como es de esperar la población afectada por la explotación del fracking, estableciéndose, asimismo, el trámite de información pública y un informe preceptivo del Consejo Asesor de Medio Ambiente. Dicho plan estratégico sectorial deberá considerar los riesgos derivados de esta técnica sobre la salud y el medio ambiente, los recursos hídricos, la gestión de los residuos y las emisiones atmosféricas, además de incluir una evaluación de riesgos y una zonificación que restrinja las áreas más sensibles.

Con carácter previo a la autorización de las operaciones, se establecen requisitos adicionales que deben cumplirse tales como la exigencia de determinar la situación de referencia del emplazamiento de la instalación y de la superficie circundante y el subsuelo potencialmente afectados, que cumpla los requisitos establecidos en la Recomendación de la Comisión Europea, de 22 de enero de 2014, a fin de determinar el estado medioambiental de partida o de referencia antes del inicio de las actuaciones. Asimismo, se añaden a los requisitos establecidos en la legislación básica sobre minería — Ley 22/1973, de 21 de julio, de Minas y Real Decreto 2857/1978, de 25 de agosto por el que se aprueba el Reglamento General para el Régimen de la Minería-e hidrocarburos —Ley 34/1998, de 7 de octubre, del sector de hidrocarburos y, en particular, sobre evaluación y prevención de riesgos contemplados en el Real Decreto 2362/1976, de 30 de julio, por el que se aprueba el Reglamento de la Ley sobre Investigación y Explotación de Hidrocarburos, de 27 de junio de 1974. Estas medidas suponen exigencias adicionales en cuanto al alcance de evaluación de riesgos de estas actividades, así como un mayor detalle sobre los planes de gestión de riesgos asociados, las medidas exigidas para prevenir o mitigar los impactos derivados, y las medidas de respuesta necesarias. Se establecen también requisitos adicionales sobre las sustancias químicas empleadas para minimizar los riesgos de contaminación. Todas estas condiciones adicionales a las ya establecidas por la legislación básica estatal se dirigen a evitar las posibles fugas y los derrames al suelo, al agua o al aire. 


\subsection{Los suelos contaminados por actividades mineras: el denominado «Plan de recuperación de suelos afectados por la minería metálica» (PRASAM)}

La CARM ha anunciado un «Plan de recuperación de suelos afectados por la minería metálica» (PRASAM) como iniciativa del Gobierno regional para abordar por fin la recuperación de los antiguos emplazamientos mineros desde una perspectiva tanto medioambiental como de salud pública y de seguridad minera. Según declaraciones expresas del consejero competente, "este plan, fruto de muchas horas de trabajo y del esfuerzo de muchos expertos, técnicos y funcionarios, es un reflejo del compromiso del Gobierno regional con la recuperación ambiental de unas zonas explotadas por la minería desde hace siglos en la Región”. El PRASAM supone tanto la actualización de estudios científicos ya existentes sobre la situación de la zona, como la realización de nuevas investigaciones, además de hacer hincapié en la vigilancia de los depósitos mineros para garantizar su seguridad estructural y de incluir actuaciones concretas de sellado y restauración en aquellos emplazamientos de mayor sensibilidad y de velar por la integridad de la salud de los habitantes de la zona.

Así, como reza el propio documento del Plan, su finalidad consiste en establecer un "marco de políticas de acción y preventivas que incluyen acciones orientadas a la prevención y a la restauración de emplazamientos afectados por la minería metálica en el ámbito de los distritos mineros de la Sierra de Cartagena y la Unión en el período 2018-2028". De modo inmediato se han puesto en marcha, según anuncia la propia Administración regional y a pesar de no haberse aprobado definitivamente el documento denominado «PRASAM», algunas acciones contempladas por el mismo. En concreto las siguientes: elaboración de un informe que recogerá todas las investigaciones científicas disponibles y determinación de la concentración natural de metales en estas zonas, además de un inventario de suelos contaminados o un estudio para medir la posible presencia de metales en el aire en el entorno de la población del Llano del Beal (Cartagena). En materia de salud pública, se informa que se está llevando a cabo un estudio epidemiológico para evaluar la exposición de la población que reside 
en algunos de estos antiguos emplazamientos mineros como El Llano del Beal, Portmán, El Estrecho, El Albujón, La Aljorra, Pozo Estrecho y La Palma.

En el «PRASAM» se establecen cuatro objetivos específicos que llevan asociadas una treintena de acciones de muy variada naturaleza: algunas constituyen obligaciones ex lege, otras son declaraciones de intenciones o anuncios de futuros planes y de otros instrumentos programáticos.

En relación al impulso para la recuperación ambiental de este tipo de suelos, el PRASAM contempla ocho acciones, sobre las que merece la pena hacer algunos comentarios. En primer lugar, se establece como medida la compatibilización de usos que, si no se declaran los suelos contaminados, no se alcanza a ver cómo los municipios competentes van a llevar a cabo dicha labor de determinación de los usos del suelo. En segundo término, se establece como medida un «Plan de actuaciones en instalaciones de residuos mineros abandonados incluidas en el inventario derivado de la Directiva 2006/21/CE ${ }^{8}$ que, como recuerda el mismo documento, debe elaborar la Dirección General de Energía y actividad industrial y minera de la CARM y que afectará a las 29 instalaciones de residuos mineros abandonados en la Región de Murcia incluidas en el Inventario iniciado en 2012 y actualizado en 2015. Sobre estas instalaciones se realizarán actuaciones de estabilización geotécnica, impermeabilización y sellado de residuos, así como de

\footnotetext{
8 “1. Los Estados miembros garantizarán que cualquier instalación de residuos a la que se haya otorgado una autorización o que esté ya en actividad el 1 de mayo de 2008 sea conforme a las disposiciones de la presente Directiva antes del 1 de mayo de 2012, salvo en lo que se refiere a las instalaciones mencionadas en el artículo 14, apartado 1, en cuyo caso el plazo será antes del 1 de mayo de 2014, y las mencionadas en el artículo 13, apartado 6, para las cuales la conformidad debe quedar garantizada con arreglo al calendario fijado en esta disposición.

2. El apartado 1 no se aplicará a instalaciones de residuos cerradas a 1 de mayo de 2008.

3. Los Estados miembros tomarán las medidas necesarias para garantizar que, a partir del 1 de mayo de 2006 y sin perjuicio del cierre de cualquier instalación de residuos tras dicha fecha y antes del 1 de mayo de 2008, los residuos de extracción se gestionan de modo que no perjudiquen el cumplimiento de lo dispuesto en el artículo 4, apartado 1, de la presente Directiva, ni cualesquiera otros requisitos medioambientales aplicables establecidos en la legislación comunitaria, incluida la Directiva 2000/60/CE.

4. Los artículos 5 , el artículo 6, apartados 3 y 5, los artículos 7 y 8 , el artículo 12, apartados 1 y 2, así como el artículo 14, apartados 1 a 3, no se aplicarán a las instalaciones de residuos que:

— hayan dejado de aceptar residuos antes del 1 de mayo de 2006,

- estén ultimando los procedimientos de cierre de conformidad con la legislación o programas pertinentes comunitarios o nacionales aprobados por la autoridad competente, $\mathrm{y}$

— vayan a quedar definitivamente cerradas a 31 de diciembre de 2010.Los Estados miembros notificarán estos casos a la Comisión antes del 1 de agosto de 2008 y garantizarán que estas instalaciones se gestionen de modo que no perjudiquen al logro de los objetivos de la presente Directiva, en particular los objetivos del artículo 4, apartado 1, y de la restante legislación comunitaria, en particular la Directiva 2000/60/CE”.
} 
restauración ambiental y paisajística, teniendo en cuenta el carácter del paisaje del entorno y de las instalaciones, con el fin de evitar colapsos de las estructuras y la contaminación del entorno. No obstante, la CARM no concreta el orden que la Administración va a seguir para abordar la restauración de estas balsas, ni el procedimiento a seguir. La única prioridad establecida es incluir en un futuro plan de actuaciones estos emplazamientos.

La tercera medida consiste en un «Programa de actuaciones de urgencia sobre el factor de movilización del material particulado/erosión eólica». En cuarto término, se prevé la elaboración de «Directrices para la restauración ecológica de los emplazamientos considerados de mayor riesgo», así como la elaboración de «Directrices para la restauración paisajística de los emplazamientos de mayor riesgo». Asimismo, se contempla la elaboración de un «Programa para la restauración hidroforestal a nivel de cuenca para minimizar riesgos». Finalmente, se añade el fomento de acuerdos voluntarios con los titulares de emplazamientos para elaborar planes de trabajo que permitan controlar y reducir la contaminación y la adecuación y puesta en valor de uno de los parajes mineros.

En fin, llama poderosamente la atención que forme parte del «PRASAM», como una de las medidas para la consecución de sus objetivos - cuando en puridad se trata de una obligación legal que la Ley 22/2011 dirige a la Administración regional-, la determinación de los valores genéricos de referencia (VGR) para la declaración de suelos contaminados, determinación que, en puridad, debería preceder a cualquier planificación en base a la cual se adopten decisiones sobre prioridades de restauración o se requiera a los propietarios de los suelos inventariados, que no contaminados en el sentido de que no han sido declarados, para que descontaminen o se hagan cargo de los costes de descontaminación.

Otras referencias en el Plan al "fomento de la investigación", a las "campañas de divulgación", a la "puesta en valor del patrimonio cultural", el "fomento de acuerdos voluntarios" y, en fin, la "asistencia a los municipios", no son más que un compendio de obligaciones genéricas extraídas del ordenamiento jurídico que nada tienen que ver con las medidas que se esperarían como parte de un verdadero plan de recuperación de suelos de este carácter y que contrastan poderosamente con las medidas ya adoptadas en otros planes autonómicos. Baste recordar, como muestra significativa de lo que se acaba de afirmar, que la 
prevista medida de "elaboración y actualización del inventario de emplazamientos contaminados" constituye una obligación de las CCAA impuesta hoy por el artículo 35 de la Ley 22/2011, de 28 de julio, de residuos y suelos contaminados y, ya con anterioridad, por la Ley 10/1998, de 21 de abril, de Residuos, todavía inaplicada en la CARM.

\section{OTRAS MANIFESTACIONES CON CONTENIDO AMBIENTAL DURANTE EL PERIODO DE REFERENCIA}

\subsection{Contaminación por nitratos: un intento ya desesperado por salvar el Mar Menor}

El Decreto 249/2018, de 19 de diciembre, aprueba las normas especiales reguladoras de una subvención a otorgar por concesión directa a la Comunidad de Regantes Arco Sur Mar Menor, del término municipal de Cartagena, para la instalación de un sistema de desnitrificación de salmueras procedentes de la desalobración por un total de 229.173,72 €.

La actividad de esta Comunidad de Regantes (https://www.cr-arcosur.com/) afecta de manera determinante a la calidad ambiental del Mar Menor que representa, como hemos tenido ocasión de subrayar de manera repetida en estas crónicas, una de las mayores lagunas litorales de Europa y la más grande de la Península Ibérica, con singulares valores ambientales que han determinado su incorporación a los Humedales de Importancia Internacional (RAMSAR) y Zonas Especialmente Protegidas de Importancia para el Mediterráneo (ZEPIM), así como la declaración de Paisaje Protegido de los Espacios Abiertos e Islas del Mar Menor, de Parque Regional de Salinas y Arenales de San Pedro del Pinatar, de Lugar de Importancia Comunitaria (LIC) «Mar Menor», y de Zona de Especial Protección para las Aves (ZEPA).

En este lugar muy emblemático de la Región de Murcia convergen múltiples usos y aprovechamientos, principalmente turísticos, recreativos y pesqueros, con un importante aprovechamiento agrícola en su entorno.

El deterioro de la calidad de sus aguas por la progresiva eutrofización de la laguna es manifiesto. Es un problema de gran complejidad técnica, ambiental y social, que exige actuar de forma combinada sobre los diferentes sectores de 
actividad cuya influencia pueda hacerse sentir sobre su estado ecológico. Existe una coincidencia sustancial en la comunidad científica sobre la necesidad de adoptar con urgencia medidas para evitar las principales afecciones al Mar Menor. El Comité de Asesoramiento Científico del Mar Menor, en diversos apartados de su «Informe integral sobre el estado ecológico del Mar Menor», de 13 de febrero de 2017 (accesible en http://servicios.laverdad.es/servicios/textos/ESTADO-INTEGRAL-MARMENOR.pdf), considera la contaminación por nitratos, que afecta también gravemente al acuífero Cuaternario, como uno de los factores que han contribuido al desequilibrio ambiental del Mar Menor, sin minusvalorar la contaminación por metales pesados o la procedente de aguas de escorrentías. Por todo ello, con el fin de favorecer el buen estado ecológico de la laguna del Mar Menor, resulta prioritario impulsar medidas preventivas, que reduzcan las aportaciones de nitratos al acuífero Cuaternario y al Mar Menor, así como medidas correctivas, que permitan la reducción de los niveles presentes y disminuyan las entradas de flujos de agua subterránea contaminados por nitratos a la laguna.

Las medidas preventivas han de ir encaminadas a favorecer el ejercicio de la actividad agraria de manera sostenible, minimizando los impactos derivados del uso de fertilizantes, así como reducir los vertidos que puedan afectar negativamente al acuífero o al Mar Menor. Por su parte, las medidas correctivas deben dirigirse a la extracción de aguas contaminadas por nitratos del acuífero y a reducir los flujos de agua subterráneos hacia la laguna.

En este contexto, la Comunidad de Regantes Arco Sur Mar Menor ha promovido diversos estudios y programas relacionados con el uso eficiente del agua y de los fertilizantes, el control de escorrentías superficiales, y sobre la cuantificación de la descarga subterránea al Mar Menor del acuífero superficial Cuaternario.

No obstante, existe en la actualidad una problemática asociada al vertido de las salmueras procedentes de una planta desalobradora, propiedad de esta comunidad de regantes, que es utilizada para tratar aguas residuales regeneradas de la EDAR del Mar Menor sur, con el fin de adecuar su calidad para el riego. Las salmueras resultantes de este proceso presentan, entre otras 
sales, una elevada concentración de nitratos que provocan un impacto ambiental indeseable tras su vertido.

La CARM colaborara financieramente con la Comunidad de Regantes Arco Sur Mar Menor para que se instale un sistema de desnitrificación de salmueras procedentes de la desalobración. Simplemente recordar que la Directiva «Nitratos» es del siglo pasado, concretamente de 1991, 1991, y su incorporación al Derecho interno español se produjo en una fecha tan lejana como 1996, 1996.

\subsection{El arruí: el negocio de la caza de una especie exótica, ¿no invasora?}

La Orden, de 18 de diciembre de 2018, de la Consejería de Empleo, Universidades, Empresa y Medio Ambiente (BORM, núm. 293, 21 de diciembre de 2018. Corrección de errores en BORM, núm. 5, martes 8 de enero de 2019), modifica la anterior Orden, de 26 de abril, de la misma Consejería sobre períodos hábiles de caza para la temporada 2018/2019 en la CARM.

Se debe recordar que la Ley 7/2003, de 12 de noviembre, de Caza y Pesca Fluvial de la Región de Murcia incluyó, en la relación de especies cazables de su Anexo, al arruí (Ammotragus lervia) y, consiguientemente, en las órdenes anuales sobre periodos hábiles de caza dicha especie era una de las que podían ser objeto de aprovechamiento cinegético, hasta que en la temporada 2017/2018, la disposición adicional tercera de la Orden, de 26 de abril de 2018, de la Consejería ("Modificación de las especies cinegéticas"), dejó de considerar dicha especie como cinegética, conforme a la STS 637/2016, que declaró la nulidad del $R D$ 630/2013, de 2 de agosto, por el que se regula el Catálogo español de especies exóticas invasoras, en lo que se refiere, entre otros extremos, a la exclusión en el referido Catálogo, de la población murciana de este bóvido. Ahora bien, con la entrada en vigor de la Ley 7/2018, de 20 de julio, de modificación de la Ley 42/2007, de 13 de diciembre del Patrimonio Natural y de la Biodiversidad, en particular, de su disposición transitoria segunda, en relación con el nuevo art. 64 ter, la referida especie vuelve a tener la consideración de especie cinegética. Conforme a la referida disposición transitoria, las CCAA pueden autorizar la práctica de la caza y de la pesca, en zonas delimitadas, de las especies que tengan relevancia social y/o económica, en sus distintas modalidades, adoptando las debidas medidas tendentes a la 
salvaguarda del medio natural y del ecosistema donde se desarrolle, y ello hasta que se aprueben los instrumentos normativos de planificación y gestión y la delimitación cartográfica del área ocupada por las especies catalogadas como exóticas invasoras, introducidas antes de la entrada en vigor de la Ley 42/2007, de 13 de diciembre. En definitiva, la presente Orden incorpora de nuevo al arruí a la relación de especies cazables de caza mayor, lo que permite autorizar su caza en las zonas delimitadas (Anexo I), para evitar que se extiendan las poblaciones fuera de las mismas, y establece, asimismo, las modalidades permitidas, períodos hábiles de caza, demás medidas para el control y precintado de trofeos.

Esta especie había provocado cierto alarmismo, una vez comprobada su capacidad expansiva, por lo que fue incluida en el «Catálogo Español de Especies Exóticas Invasoras» de 2011, listado de especies consideradas una amenaza para la diversidad biológica nativa en los ecosistemas en donde se han introducido. Por su parte, y con el fin de mejorar la aplicación de las políticas de lucha contra las especies exóticas invasoras, el Gobierno aprobó el Real Decreto 630/2013, de 2 de agosto, por el que se regula el Catálogo español de especies exóticas invasoras, que venía a solucionar los problemas de aplicación que se derivaban del RD de 14 de noviembre de 2011 que había sido objeto de recursos por parte de varias CCAA y de algunos sectores afectados. EI RD de 2011 fue objeto de dos autos del TS que motivaron la anulación, por parte del Consejo de Ministros, de diversos artículos, disposiciones y de su anexo II y se acordaba iniciar el procedimiento para su modificación. La modificación se justificaba con el objetivo de dar seguridad jurídica a las actividades relacionadas con las especies exóticas invasoras como la caza y la pesca deportiva, y de solucionar los problemas de aplicación que la normativa anterior había provocado. Posteriormente, como consecuencia del recurso de varias organizaciones no gubernamentales, el STS 637/2016, de 16 de marzo, modificó la lista de especies catalogadas y anuló varias disposiciones del RD 630/2013. Esta sentencia del Alto Tribunal generó gran preocupación por sus efectos económicos y sociales, al implicar la prohibición genérica de posesión, transporte, tráfico y comercio de ejemplares vivos de varias especies que son objeto de aprovechamiento piscícola o cinegético, y supuso la imposibilidad de la práctica de la caza y pesca 
deportivas de las especies catalogadas, salvo en el marco de campañas de control y erradicación, especies entre las que se encontraba el arruí. Ello supuso, en la Región de Murcia, un impacto económico negativo para los municipios rurales en los que estas actividades deportivas, turísticas y de ocio se llevan a cabo.

La CARM defiende, de la mano de la Real Federación Española de Caza (RFEC), que este mamífero bien puede ser calificado como exótico, toda vez que no se trata de una especie autóctona y fue introducido por el hombre en el parque natural de Sierra Espuña hace ya más de 40 años, pero que no existen razones para que integre el listado de especies invasoras. Ello se debe a que, según concluyen no pocos documentos científicos -entre ellos, varios informes recientes encargados por la propia Consejería-, ni su presencia compromete gravemente al medio ambiente, ni desplaza a otras especies, como la cabra montesa. Así, en base a esas razones, reclamó al Ministerio que procediera a descatalogar al arruí como especie invasora, lo que se traduciría en una especie de "indulto" que lo salvaría de la amenaza de erradicación que pesaba sobre este animal. Ello no impediría, sin embargo, que la Consejería pudiera seguir acometiendo labores de control poblacional, pues el Plan de Ordenación del Parque Natural de Sierra Espuña cifra en 300 la cifra recomendable de arruís, frente al millar largo que, según algunas estimaciones, aún habita esa área montañosa.

Como consecuencia del iter descrito, y por tratarse, desde luego, de un asunto especialmente sensible para las CCAA, como administraciones directamente responsables de la gestión de estas especies y de la regulación de la actividad cinegética y piscícola, la Ley 7/2018, de 20 de julio, de modificación de la Ley 42/2007, de 13 de diciembre, del Patrimonio Natural y de la Biodiversidad viene a ofrecer una solución que según su exposición de motivos compatibiliza la protección del medio ambiente, de conformidad con la STS antes referida, y la actividad y el empleo de los sectores cinegético y piscícola, teniendo en cuenta lo dispuesto en el Reglamento 1143/2014, de 22 de octubre, del Parlamento Europeo y del Consejo, sobre la prevención y la gestión de la introducción y propagación de especies exóticas invasoras en cuya aprobación participó 
activamente España, debiendo valorar, en las actuaciones a seguir, las especies que proporcionan beneficios sociales y económicos ${ }^{9}$.

Esta modificación de la LPNB de 2007, según declara la exposición de motivos de la Ley de reforma, tiene por objeto compatibilizar la imprescindible lucha contra las especies exóticas invasoras con su aprovechamiento para la caza y la pesca en aquellas áreas que, al estar ocupadas desde antiguo, su presencia no suponga un problema ambiental ${ }^{10}$.

En conclusión, la Orden CARM que reseñamos ejecuta la nueva redacción legal para permitir de nuevo la actividad cinegética sobre el arruí en el territorio de la Región de Murcia, especie proveniente de los montes Atlas de Marruecos que, como se ha señalado, se introdujo en Sierra Espuña en los años 70 del siglo pasado.

\subsection{Energías renovables}

La Orden, de 21 de diciembre de 2018, de la Consejería de Fomento e Infraestructuras, aprueba las bases reguladoras de las ayudas destinadas al fomento de autoconsumo de energías renovables, con la instalación de energía solar fotovoltaica en viviendas conectadas y no conectadas a la red de

\footnotetext{
${ }^{9}$ Vid. Beltrán Castellanos, J. M. (2019), Fauna exótica invasora, Reus, Madrid.

${ }^{10}$ Así, se modifica el apartado b) y se incluye un nuevo apartado l) en el art. 2. La nueva redacción establece que:

«b) La conservación y restauración de la biodiversidad y de la geodiversidad mediante la conservación de los hábitats naturales y de la fauna y flora silvestres. Las medidas que se adopten para ese fin tendrán en cuenta las exigencias económicas, sociales y culturales, así como las particularidades regionales y locales.»

«l) El mantenimiento y la adaptación de las poblaciones de todas las especies de aves que viven normalmente en estado salvaje en un nivel que corresponda en particular a las exigencias ecológicas, científicas y culturales, habida cuenta de las exigencias económicas y recreativas».
}

Por otra parte, se añaden los siguientes apartados al art. 3 con la siguiente redacción:

«22bis. Introducción: Se refiere al movimiento por acción humana, voluntaria o accidental, de una especie fuera de su área de distribución natural. Este movimiento puede realizarse dentro de un país, o entre países o zonas fuera de la jurisdicción nacional.»

29bis. Recursos zoogenéticos para la agricultura y la alimentación: Aquellas especies de animales que se utilizan, o se pueden utilizar, para la producción de alimentos, la agricultura, la ganadería o la alimentación y que sean declaradas como tal, mediante Orden, por el Ministerio de Agricultura y Pesca, Alimentación y Medio Ambiente o que tengan reconocida dicha consideración por convenios u organismos internacionales de carácter oficial.»

29ter. Especie naturalizada: Especie exótica establecida en el ecosistema con carácter permanente, introducida legalmente antes de la entrada en vigor de la presente Ley, y respecto de la que no existan indicios ni evidencias de efectos significativos en el medio natural en que habita, presentando además un especial interés, social o económico». 
distribución en la Comunidad Autónoma de la Región de Murcia (BORM, núm. 294, de 22 de diciembre de 2018).

La CARM, de acuerdo con las competencias en materia de vivienda establecidas en el art. 148.1.3. ${ }^{a}$ CE asumidas, con carácter exclusivo, en virtud del art. 10 EARM (LO 4/1982, de 9 de junio) actúa, entre otros, en los ámbitos de la calidad de la edificación y de la rehabilitación del parque inmobiliario regional. En este contexto, para lograr además objetivos de eficiencia energética, se considera que para reducir las emisiones de gases de efecto invernadero en la Comunidad y disminuir su dependencia con respecto a las importaciones energéticas se debe fomentar el uso de instalaciones de mayor eficiencia energética. El incentivo de la instalación de estos equipos de energía solar fotovoltaica, persigue que el consumo de energía en viviendas conectadas y no conectadas a la red de distribución (unifamiliares aisladas o agrupadas en fila y para viviendas ubicadas en edificios de tipología residencial colectiva), se traduzca en un ahorro en la factura, en la reducción de las emisiones de $\mathrm{CO}_{2}$, y se transforme en energía renovable y limpia. La propia orden subraya que esta ayuda a los particulares se realiza no solo con el objetivo de promover la instalación de equipos más eficientes y menos contaminantes sino también para estimular la actividad productiva de este tipo de equipos e impulsar la actividad comercial y de las empresas instaladoras.

\subsection{La declaración de bienes de interés cultural}

A) El Decreto 265/2018, de 27 de diciembre, declara bien de interés cultural con categoría de sitio histórico, «La Sierra del Cuchillo» de Yecla (BORM, núm. 299, de 29 de diciembre de 2018).

B) El Decreto 14/2019, de 27 de febrero, declara bien de interés cultural, con categoría de monumento, la «Basílica de Nuestra Señora de la Caridad», en Cartagena (BORM, núm. 54, 6 de marzo de 2019).

C) El Decreto 15/2019, de 27 de febrero, declara bien de interés cultural, con categoría de monumento, la «Capilla Marraja de Nuestro Padre Jesús Nazareno», en Cartagena (BORM, núm. 54, 6 de marzo de 2019). 
D) El Decreto 29/2019, de 13 de marzo, declara bien de interés cultural con categoría de sitio histórico, el «Monte Miral» o "Cabezo de San Ginés de la Jara», en el término municipal de Cartagena (BORM, núm. 67, 22 de marzo de 2019).

E) El Decreto 34/2019, de 20 de marzo, declara Monumento Natural a las «Gredas de Bolnuevo» (BORM, núm. 73, 29 de marzo de 2019).

En relación a este último, la Ley 42/2007, de 13 de diciembre, del Patrimonio Natural y de la Biodiversidad contempla, en su clasificación de los espacios naturales protegidos, la categoría de Monumentos Naturales. Y como tales, según su art. 34, se han de declarar los espacios o elementos de la naturaleza constituidos básicamente por formaciones de notoria singularidad, rareza o belleza, que merecen ser objeto de una protección especial; considerándose también Monumentos Naturales, entre otros, las formaciones geológicas, los yacimientos paleontológicos, los estratotipos y demás elementos de la gea que reúnan un interés especial por la singularidad o importancia de sus valores científicos, culturales o paisajísticos. El art. 37 de la Ley 42/2007 atribuye a las CCAA, en su ámbito territorial, la competencia para la declaración y la determinación de la fórmula de gestión de sus espacios naturales protegidos. En este ámbito competencial autonómico, y tal como establece el art. 11 EARM, corresponde a la Región de Murcia el desarrollo legislativo y la ejecución en materia de espacios naturales protegidos, en el marco de la legislación básica del Estado y en los términos establecidos en la misma. En este sentido, y en concreto, el art. 48. 3 de la Ley 4/1992, de 30 de julio, de Ordenación y Protección del Territorio de la Región de Murcia, dispone que compete al Consejo de Gobierno la declaración de los Monumentos Naturales mediante Decreto.

En particular, la singularidad, belleza y rareza de los elementos naturales y formaciones geológicas de las Gredas de Bolnuevo, en el término municipal de Mazarrón, hacen que este espacio sea merecedor de una protección especial que conlleve la adopción de medidas de conservación que aseguren su preservación. Procede en consecuencia a su declaración como espacio natural protegido, cuya clasificación en la categoría de Monumento Natural queda justificada por el relevante interés geológico del enclave y su valor científico, cultural y paisajístico 
Por desgracia, si nuestro curioso lector tuviera la oportunidad de visitar esta entrañable y generosa tierra podría comprobar como esta rareza geológica ha quedado encerrada por un desafortunado desarrollo urbanístico que, a pesar de todo, no ha conseguido desmerecer su belleza natural a las puertas de las calas de Bolnuevo, uno de los pocos espacios que todavía mantienen el contorno de la costa mediterránea que evoca mitos y leyendas.

\subsection{Los problemas que causa la proliferación del conejo de monte}

La Orden, de 15 de febrero de 2019, de la Consejería de Empleo, Universidades, Empresa y Medio Ambiente, adopta medidas para la prevención de daños causados por la proliferación de conejos (BORM, núm. 53, de 5 de marzo de 2019).

En efecto, la proliferación del conejo de monte (Oryctolagus cuniculus), con los consiguientes daños y perjuicios que esta especie puede causar a la salud humana, a la agricultura y a infraestructuras de carácter viario, motivaron que en años anteriores, y con fundamento en el art. 45 de la Ley 7/2003, de 12 de noviembre de Caza y Pesca Fluvial de la Región de Murcia, fueran declarados determinados términos municipales como «Comarca de Emergencia Cinegética Temporal», mediante orden de la Consejería competente en materia de caza. Una vez comprobado que vuelven a repetirse las mismas circunstancias, se procede con pequeñas modificaciones al dictado de una nueva orden, dada la dificultad de controlar estas poblaciones con los métodos habituales, mediante la regulación establecida en las órdenes anuales de vedas, o mediante permisos especiales concedidos como consecuencia de daños. Las medidas que se adoptan tratan de armonizar los intereses de los sectores agrícola y cinegético, con la necesaria prevención ante la aparición de enfermedades infecciosas transmitidas por ácaros ixodoideos (garrapatas).

\subsection{Deporte y naturaleza: la necesidad de proteger los senderos}

Ley 2/2019, de 1 de marzo, de los senderos señalizados de la Región de Murcia (BORM, núm. 54, 6 de marzo de 2019) tiene en cuenta que las actividades deportivas en la naturaleza y en el medio rural (el senderismo, la bicicleta de montaña, las rutas ecuestres, y otras) representan prácticas deportivas y 
recreativas que aprovechan para su desarrollo la existencia de veredas, caminos, senderos, vías pecuarias, caminos históricos, vías verdes, cañadas u otro tipo de viales de uso tradicional o moderno. En las últimas décadas, a la práctica de esas actividades deportivas, se ha venido sumando un importante sector de turismo activo y de naturaleza, con demanda cada vez más creciente. Por otra parte, han convivido y se han multiplicado el uso de la red de senderos con fines culturales, educativos, medioambientales y saludables.

La Ley reseñada parte de la realidad tangible de que existe una amplia red de recorridos señalizados en la CARM, con más de 3.000 kilómetros señalizados y homologados, entre rutas de senderismo, bicicleta de montaña, itinerarios ecuestres, ecoturísticos, Caminos de la Cruz de Caravaca y senderos naturales, delimitados en 150 recorridos diferentes. Todos ellos mantienen la pervivencia de actividades históricas y tradicionales en el medio natural y rural, y hacen posible la práctica de actividades deportivas en la naturaleza cada vez más demandadas. Esta amplia red de los senderos o viales no motorizados, y todos los proyectos de futuro que puedan surgir, requieren de instrumentos legales que regulen su conservación, renovación y permitan una gestión ágil y eficaz que garantice calidad, seguridad y homogeneidad de los mismos. Históricamente la creación de esta red de senderos ha ido surgiendo promovida desde administraciones y organizaciones muy diversas, que han actuado sobre el territorio con distintas competencias y objetivos dispares, cuyo resultado final ha sido la situación actual alcanzada, caracterizada por la existencia de una heterogeneidad de sistemas y marcas empleadas para el balizado de los recorridos, dispersión de conceptos y definiciones sobre el uso y naturaleza de los senderos, que generan incertidumbre, conflictos y problemas para el mantenimiento, conservación y expansión a futuro de la red.

Se ha constatado, en consecuencia, la necesidad de establecer un marco regulatorio homogéneo que ordene y permita el control de la Administración competente sobre esta red de senderos y, en general, sobre el uso de viales no motorizados en la CARM. Esta ley contempla como novedad la regulación de los senderos no motorizados como equipamientos deportivos, en el marco de la Ley 24/2015, de la Actividad Física y del Deporte de la Región de Murcia, respetando las regulaciones sobre senderos en la Región de Murcia en otros ámbitos tales 
como el turismo, los espacios naturales protegidos, las vías pecuarias, la regulación forestal, la legislación de régimen local y de aguas. La presente Ley de Regulación de los Senderos Señalizados tiene en cuenta la evolución del número de personas que utilizan los espacios naturales que aumenta de forma constante y el desarrollo de nuevas formas de uso y disfrute de esos entornos que deben ser revisados y gestionados por los poderes públicos. Su capítulo I (arts. 1-3) contiene las disposiciones generales y precisa el objeto de la misma, que es la regulación de los senderos de la Región de Murcia que revistan la condición de recursos deportivos y recreativos. El capítulo II (arts. 4-5) establece la clasificación de los senderos y crea la Red de Senderos de la Región de Murcia y el Registro de Senderos de la Región de Murcia de uso público. Este registro sirve como instrumento vertebrador de naturaleza administrativa de la información relativa al conjunto de senderos autorizados y homologados por la consejería con competencias en la materia en la Comunidad Autónoma de la Región de Murcia. El capítulo III (arts. 6-13) precisa las atribuciones de la consejería con competencias en la materia y de las funciones de las entidades colaboradoras, en relación con el procedimiento de autorización, homologación, modificación y, en su caso, cancelación de reconocimiento de senderos homologados de la Red de Senderos Señalizados de la Región de Murcia y del Registro de Senderos Señalizados de la Región de Murcia. Por su parte, el capítulo IV (art. 14) determina el régimen sancionador de estas instalaciones en la Región de Murcia, estableciendo con carácter general las que se encuentran reguladas por la Ley 8/2015, de 24 de marzo, de la Actividad Física y del Deporte de la Región de Murcia. Finalmente, la disposición adicional primera se centra en señalar el carácter protegido de las marcas oficiales con las que deben identificarse los distintos itinerarios para el Registro de Senderos Señalizados; la disposición adicional segunda amplía la utilización del procedimiento de homologación y autorización previsto en esta ley a las vías de escalada equipadas; la disposición adicional tercera comenta el caso de los itinerarios señalizados de responsabilidad estatal o internacional que se den en el territorio de la Región de Murcia; la disposición adicional cuarta prevé la creación de una Comisión Mixta de Senderos de la Región de Murcia con el fin de facilitar la coordinación del trabajo contemplado en esta ley entre las diferentes Administraciones y agentes señalados; la disposición transitoria única establece 
un plazo para la regularización de los senderos señalizados existentes con anterioridad a la entrada en vigor de la ley que revistan la condición de recursos deportivos, culturales, educativos y recreativos; la disposición derogatoria única deroga cuantas disposiciones de igual o inferior rango se opongan o contradigan lo dispuesto en la ley; y las disposiciones finales modifican la Ley 3/2018, de 26 de marzo, por la que se ordena el ejercicio de las profesiones del deporte en la Comunidad Autónoma de la Región de Murcia, establecen la facultad de la persona titular de la consejería con competencias en deportes para el desarrollo de la regulación y la ejecución de esta ley y la entrada en vigor de la misma.

\subsection{Promoviendo las actividades agropecuarias de proximidad}

La Ley 4/2019, de 3 de abril, de Venta Local de Productos Agroalimentarios de la Comunidad Autónoma de la Región de Murcia (BORM, núm. 80, 6 de abril de 2019), con apoyo en el art. 10, Uno 6, EARM, que atribuye a la CARM la competencia exclusiva en materia de agricultura y ganadería, que comprende la regulación del sector agroalimentario y de los servicios vinculados, la sanidad animal y vegetal y la seguridad alimentaria y el desarrollo integral del mundo rural. Tiene, asimismo, en cuenta la competencia exclusiva en materia de comercio interior (art. 10. Uno. 34 EARM) y la competencia de desarrollo legislativo y ejecución en materia de defensa del consumidor y usuario (art. 11. 7 EARM).

El legislador murciano, entendiendo que el funcionamiento adecuado y transparente de la cadena alimentaria exige una distribución equitativa de los beneficios entre todos sus integrantes, regula y fomenta fórmulas que corrijan los desequilibrios en favor de los productores primarios y de los consumidores finales de acuerdo a los principios de interés general y las nuevas demandas de la sociedad. El interés por potenciar un nuevo sistema de comercialización de productos agroalimentarios, más próximos a las zonas de producción, con criterios sociales, ecológicos o de salud tiene una repercusión positiva en términos de desarrollo rural al posibilitar la instalación, puesta en marcha o consolidación de muchos proyectos de emprendimiento que dinamizan los territorios rurales y que suponen un aporte en términos de calidad y diferenciación a nuestro sistema alimentario en línea con el Reglamento (UE) 
1305/2013, del Parlamento Europeo y del Consejo, de 17 de diciembre de 2013, relativo a la ayuda al desarrollo rural a través del Fondo Europeo Agrícola de Desarrollo Rural (Feader) y por el que se deroga el Reglamento (CE) 1698/2005 del Consejo, que establece que una de las prioridades de desarrollo rural de la UE es fomentar la organización de la cadena alimentaria, mejorando tanto los resultados económicos y medioambientales de las explotaciones agrícolas y las empresas rurales como la eficiencia del sector de la comercialización y transformación de productos agrícolas. Uno de los instrumentos para lograrlo son las cadenas cortas de distribución y los mercados locales.

Otro ámbito en el que la UE regula la cadena alimentaria es en el de la higiene de los alimentos en cada una de las fases de la cadena. Tanto el Reglamento (CE) 852/2004 del Parlamento Europeo y del Consejo, de 29 de abril de 2004, relativo a la higiene de los productos alimenticios, como el Reglamento (CE) 853/2004 del Parlamento Europeo y del Consejo, de 29 de abril de 2004, por el que se establecen normas específicas de higiene de los alimentos de origen animal, excluyen de sus respectivos ámbitos de aplicación el suministro directo de pequeñas cantidades de productos primarios por parte del productor al consumidor final o a establecimientos locales de venta al por menor, dejando a los EEMM la regulación de este tipo de actividades con arreglo a su derecho nacional, por la estrecha relación entre el productor y el consumidor.

El RD 640/2006, de 26 de mayo, regula determinadas condiciones de aplicación de las disposiciones comunitarias en materia de higiene, de la producción y comercialización de los productos alimenticios, y en él se establece que la autoridad competente podrá autorizar el suministro directo en determinadas condiciones, de pequeñas cantidades de productos primarios al consumidor final por parte del productor. Este RD abre la posibilidad a que con posterioridad se regule el suministro y venta de productos agroalimentarios siempre atendiendo a los criterios de cercanía, cantidad y calidad tradicional de los mismos. La «cadena corta» de distribución de alimentos, en la que interviene un número limitado de agentes económicos, con relaciones geográficas y sociales de cercanía entre productores, transformadores y consumidores, es una de las fórmulas que pueden utilizarse para corregir los desequilibrios en la cadena alimentaria. Por ello, esta ley declara tener como un primer objetivo, dentro del 
marco jurídico-normativo expuesto, la regulación y el fomento en el ámbito de la CARM de dos modalidades de venta local, que son la venta directa y la venta en canal corto de comercialización. En la primera, pequeñas cantidades de productos primarios o elaborados por un productor agrario o forestal son vendidos o suministrados directamente por este al consumidor final. En la segunda, el productor entrega dichos productos a un establecimiento local, una empresa de distribución o cualquier otra fórmula que se establezca, que sólo puede venderlos o suministrarlos a un consumidor final. Por otra parte, la normativa comunitaria sobre higiene de los alimentos antes citada prevé que las condiciones higiénico-sanitarias sean suficientemente flexibles para garantizar la existencia de soluciones a situaciones específicas sin poner en peligro la seguridad alimentaria. En este sentido, dicha normativa comunitaria prevé, tanto para la producción primaria como para las etapas posteriores, la utilización de guías de prácticas correctas de higiene que deberán ayudar a las empresas a aplicar los procedimientos basados en el análisis de peligros y puntos críticos de control. Asimismo, la normativa comunitaria prevé un procedimiento para que los EEMM puedan adaptar determinados requisitos higiénicos, aplicables en cualquiera de las fases de producción, transformación o distribución de alimentos, bien para poder seguir utilizando métodos tradicionales, bien para dar respuesta a las necesidades de las empresas situadas en regiones con limitaciones geográficas especiales, o bien en relación con los requisitos estructurales de los establecimientos.

Por otra parte, para dar cumplimiento a la previsiones de la legislación de la UE, la presente ley tiene también como segundo objetivo prever en qué condiciones podrán adaptarse las condiciones de higiene de los alimentos, manteniendo en todo caso los objetivos y los principios que establece la normativa comunitaria sobre higiene de los alimentos: la seguridad alimentaria y la inocuidad de los alimentos; los requisitos de etiquetado, publicidad y presentación; la trazabilidad y la responsabilidad de los distintos agentes de la cadena alimentaria. Asimismo, el Reglamento (CE) 853/2004 deja fuera del ámbito de aplicación del «Paquete Higiénico Sanitario» el suministro directo por parte del productor de pequeñas cantidades de carne procedente de aves de corral y lagomorfos sacrificados en la explotación y dirigidos al consumidor final o a establecimientos locales de 
venta al por menor, que suministran directamente dicha carne al consumidor final, e igualmente señala que este tipo de suministro debe regularse por los EEMM. El legislador murciano considera que, en la actualidad, es posible permitir el suministro directo por parte del productor de pequeñas cantidades de carne procedente de aves de corral y lagomorfos sacrificados en la explotación, favoreciendo con ello el desarrollo del medio rural y los canales cortos de distribución, siempre que se reúnan una serie de requisitos que garanticen el cumplimiento de los objetivos de higiene.

\section{FINAL: UNA MALA NOTICIA PARA LA ANHELADA RECUPERACIÓN AMBIENTAL DE LA BAHÍA DE PORTMÁN}

Por desgracia, esta crónica debe terminar constatando que la Dirección General de Sostenibilidad de la Costa y del Mar del Ministerio para la Transición Ecológica ha paralizado temporalmente el contrato de obras del proyecto de regeneración y adecuación ambiental de la bahía de Portmán hasta que se produzca una nueva adjudicación. Esta decisión responde a la SAN del pasado 27 de febrero, que resolvió el recurso que presentó Acciona contra la adjudicación de estos trabajos a la UTE Marco Obra Pública SA-Ciomar SL, y que obliga a la $A G E$ a retrotraer las actuaciones para que se dicte un nuevo acuerdo de adjudicación.

Según nos cuenta el diario "La Verdad"11, el documento ministerial comprueba que «con el desarrollo de los trabajos, se han detectado diversos problemas para la ejecución de la obra», entre los que destacan los «problemas relativos al tratamiento del agua del dragado por su posible contaminación con metales pesados; y problemas derivados de la posible contaminación y turbidez provocados por el dragado a realizar». Por esta razón, el Ministerio anuncia que va a priorizar la seguridad para las personas y el medio ambiente en el nuevo proceso de adjudicación. A estos graves problemas detectados, se suman los de inestabilidad «del material que debe dragarse de la bahía y depositarse en la Corta San José» y otros «derivados del proceso de secado del material a dragar». Aunque, advierte el Ministerio, la sentencia no es firme, la adjudicación

\footnotetext{
${ }^{11}$ La Verdad, "El Ministerio paraliza temporalmente la regeneración de la bahía de Portmán”, 12 de abril de $2019<$ https://www.laverdad.es/> [última consulta, 1 de julio de 2019].
} 
del contrato queda anulada y las obras de regeneración de la bahía suspendidas temporalmente hasta que se resuelva la nueva adjudicación, «aplicando el principio de prudencia». Igualmente, en su decisión, el Ministerio de Transición Ecológica da también por nulos los contratos encargados a Tragsa, Grusamar Ingeniería y Consulting SL y Tragsatec, que resultaron de la modificación del contrato firmado con la UTE Marco Obra Pública SA-Ciomar SL, relativos a la seguridad y salud del proyecto, la asistencia técnica a la dirección de obra y la gestión para la elaboración de documentos derivados de la aplicación del RD 975/2009.

El mismo diario mencionado, subraya que las organizaciones vecinales y ecologistas culpan de la situación al anterior Gobierno de Mariano Rajoy, ya que «el proyecto en ejecución se fraguó en un largo proceso desde la firma del convenio en el año 2006 entre las tres administraciones, y que fue aprobado con un amplio consenso en 2011, comprometida su financiación plurianual y licitado por un importe de 79 millones de euros»; «las obras deberían estar hoy plenamente terminadas y la Bahía recuperada si, tras el cambio de gobierno, el Ministerio no hubiera anulado en 2012 la licitación y suspendido las obras iniciadas, sustituyéndolo después por un irresponsable proceso para declarar recurso minero la Bahía de Portmán por parte de la Comunidad Autónoma, y entregar su explotación, a través de una concesión por 10 años, a una empresa fraudulenta creada por Aria Internacional, que de la mano inicialmente de Acciona, vendió la quimera de la regeneración total de la Bahía de Portmán a coste cero para el erario público». Estas denuncias, de las que ya nos hemos hecho eco en estas crónicas desde nuestro sureste peninsular, denuncian que: «solo cuando fue detenido el responsable de la empresa y se hizo público que estaba en concurso de acreedores, el Ministerio desistió y, tras perder 4 años, volvió a licitar en 2015 el proyecto aprobado en 2011. Pero lo hizo introduciendo dos cambios que están pesando en los problemas actuales, reducir drásticamente el precio hasta los 59 millones euros, e incluir en el pliego como mejora la posibilidad de valorizar los minerales de los estériles dragados, en un intento de justificar los años perdidos».

Por encima de las respectivas imputaciones de culpabilidad por la situación creada — que a nada ni a nadie ayudan—, la presente crónica deja constancia 
de la tristeza y hasta del hastío que producen estos repetidos eventos que, si no fuera por los daños ambientales y a la salud de los habitantes afectados, serían más propios de las descripciones berlanguianas de una España que, ¡ay! creíamos, pertenecía a un pasado felizmente superado. 